\title{
UMA ABORDAGEM GEOHISTÓRICA E ETNOGEOGRÁFICA DO BARROCO MINEIRO APLICADA AOS ESTUDOS DA PAISAGEM NAS REGIÕES DE ANTIGA MINERAÇÃO DO BRASIL
}

\author{
A GEOHISTORICAL AND ETHNOGEOGRAPHICAL APPROACH ON \\ BAROQUE PERIOD IN MINAS GERAIS APPLIED TO LANDSCAPE \\ RESEARCH IN FORMER MINING REGIONS OF BRAZIL
}

UNE APPROCHE ETNOGEOGRAPHIQUE ET GEOHISTORIQUE DU PÉRIODE BAROQUE DANS L' ÉTAT DE MINAS GERAIS DIRIGÉE AUX ÉTUDES DE LA PAYSAGE DANS LES RÉGIONS DE L'ANCIÉNNE EXPLOITATION MINIĖRE AU BRÉSIL

\author{
Henrique Moreira de Castro \\ Secretaria de Governo - Prefeitura Municipal de Betim (MG) \\ Rua Emílio Ricaldoni 141/ 204 - João Pinheiro \\ 30.530.210 Belo Horizonte (MG) \\ hmc8@terra.com.br \\ José Antônio Souza de Deus \\ Professor Associado - Instituto de Geociências/ IGC - UFMG \\ Rua Mangabeira, 268/ 401 - Santo Antônio \\ 30.350.170 Belo Horizonte (MG) \\ jantoniosdeus@uol.com.br
}

\begin{abstract}
Resumo
Esse trabalho discute uma experiência didática direcionada à investigação das relações e interfaces entre diferentes campos do conhecimento, viabilizando a reelaboração de idéias em torno do Período Barroco (e privilegiando paradigmas de interpretação da Geografia Cultural). A metodologia inclui: pesquisa bibliográfica e cartográfica; problematização e formação de grupos de discussão sobre categorias conceituais envolvidas; reconhecimentos de campo; contextualização e sistematização dos dados. $\mathrm{O}$ trabalho fez a leitura de elementos iconográficos do período tendo se direcionado a alunos de graduação e pós-graduação em interação com professores do ensino fundamental/médio e propiciando um diálogo com a Geografia Escolar. Foi privilegiada aí a releitura da influência dos afrodescendentes na consolidação de um substrato cultural regional próprio a partir da postulação de que a incorporação da vertente africana no entendimento da cultura nacional permanece como questão que ainda demanda análise mais criteriosa. O Barroco mesclou características profanas e sagradas e ainda produz repercussões na realidade atual. São colocadas em evidência na pesquisa
\end{abstract}




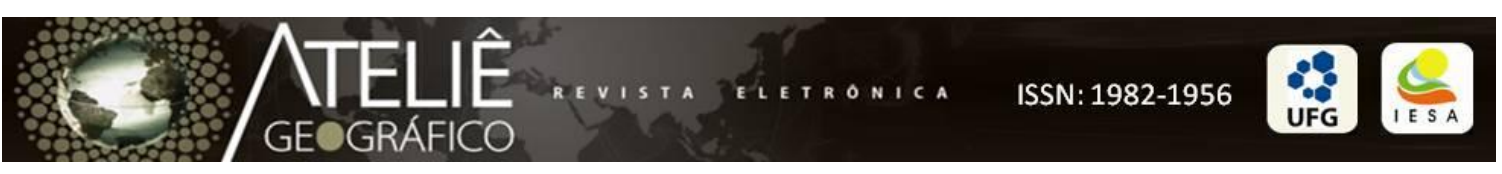

as mixagens interculturais que representaram códigos para a amalgamação de um novo universo cultural regional, cheio de diversidade e dinamismo.

Palavras-Chave: Barroco, Geografia Escolar, Paisagens Culturais, Mixagens Interculturais, Percepção do Espaço Vivido.

\begin{abstract}
This paper discusses an experience that has investigated the relations and interfaces between different fields of knowledge, enabling reworks about the ideas around the Baroque period (and privileging ethnogeographical paradigms of interpretation). The methodology included: bibliographic research; problematization and group discussion on the conceptual categories involved; field works and data systematization. The paper gives a reading of iconographic elements of this historic period and is directed to graduate/post graduate students in interaction with elementary school teachers, allowing so a dialogue with the School Geography. In the research, it was privileged the reading of African descents' influence in the consolidation of a unique cultural substrate (from postulations that assume that the incorporation of the African component in the understanding of Brazilian culture remains a strategically question to understand in national scale and that still requires more careful analysis). The Baroque mixed profane and sacred characteristics and still reverberates in the current reality nowadays. The investigation placed in the evidence particularly the cross-cultural mixes which represented then codes for amalgam a new cultural universe, full of dynamism.
\end{abstract}

Keywords: Baroque, School Geography, Cultural Landscapes, Intercultural Mixes, Environmental Perception

\title{
Résumé
}

Cet article examine l'expérience en enseignement dirigé à l'enquête sur les interfaces entre les différents champs du savoir, permettant la refonte des concepts autour du période Baroque (et en utilizant paradigmes de l'interprétation de la géographie culturelle et de la perception). La méthodologie comprenait: récherche bibliographique/cartographique, le questionnement et la formation de groupes de discussion sur les catégories conceptuelles travaillées; reconnaissance de champ; et systématisation des informations. Le document a donné une lecture des éléments iconographiques de l'époque et s'adresse aux étudiants de premier cycle en interaction avec les enseignants dans le primaire ou au secondaire, ce qui permet un dialogue avec la géographie scolaire. A l'intérieur il y avait la lecture de l'influence d'ascendance africaine dans la consolidation d'un substrat culturel particulaire a partir de la postulation que l'incorporation du composant africain dans la compréhension de la culture brésiliènne reste un problème national qui nécessite d'une analyse plus minutieuse. Le Baroque a mélangé profanes et sacrées characteristiques et résonne encore dans la réalité actuelle. Sont mis en évidence dans la recherche en particulier des brassages interculturels qu'ont représenté lors des codes pour la fusion d'un nouvel univers culturel, plein de dynamisme.

Mots-Clés: Baroque, Géographie à L'École, Paysages Culturels, Brassages Interculturels, Perception de l' Espace Vécu. 


\section{Introdução}

Esse trabalho propõe uma abordagem conceitual e metodológica centrada no cotidiano escolar e materializada numa proposta de ensino transdisciplinar, direcionada à investigação das conexões e interfaces entre a Geografia, a História e a Arte. O postulado básico dessa intervenção em sala de aula consistiu num trabalho destinado à aquisição de capacidade pelos alunos para a utilização de diferentes linguagens, incluindo-se aí, a cultura e memória visuais (CASTRO, DEUS, 2009; DEUS, 2010). Os alunos que participaram da experiência foram graduandos e pós-graduandos de cursos de duas unidades acadêmicas da Universidade Federal de Minas Gerais - em Belo Horizonte: Instituto de Geociências (cursos de Geografia - Licenciatura/Bacharelado e Pós-Graduação; e Turismo ${ }^{1}$ - ambos vinculados ao Departamento de GeografiaIGC/UFMG); e Faculdade de Educação (Curso de Formação Intercultural de Educadores Indígenas ${ }^{2}$ - FIEI - FaE). Os estudantes envolvidos com a prática matricularam-se em disciplinas optativas na área de Geografia Cultural. O recorte temático selecionado para a viabilização e desenvolvimento dessa práxis foi uma paisagem cultural sugestiva e marcante na história mineira: o Barroco.

\section{Procedimentos Metodológicos}

Os passos metodológicos utilizados para a operacionalização da prática educativa corresponderam a: pesquisa bibliográfica, cartográfica e documental; problematização sobre as categorias teórico-conceituais envolvidas; formação de grupos orientados para a investigação dos conceitos e temas em pauta; reconhecimentos de campo nas regiões de Ouro Preto, Mariana (Quadrilátero Ferrífero); Diamantina e Minas Novas (Vale do Jequitinhonha), além de contextualização e sistematização das informações e dados.

\footnotetext{
${ }^{1}$ Graduação em Geografia - Disciplinas: Geociências e Cultura; Tópicos em Geografia Humana e Tópicos Especiais em Geografia I; Graduação em Turismo - Disciplina: Tópicos em Planejamento do Turismo I; Pós-Graduação em Geografia - Disciplina: Tópicos Especiais IV.

${ }^{2} \mathrm{O}$ curso FIEI/FaE é direcionado aos professores indígenas mineiros das etnias Maxakalí, Krenak, Xakriabá, Pataxó, Kaxixó, Xukuru-Kariri e Pankararu, propondo-se à construção de um diálogo intercultural e desdobrando-se em três eixos de atuação intitulados: "A Escola e Seus Sujeitos", "Múltiplas Linguagens" e "Conhecimento da Realidade Socioambiental".
} 


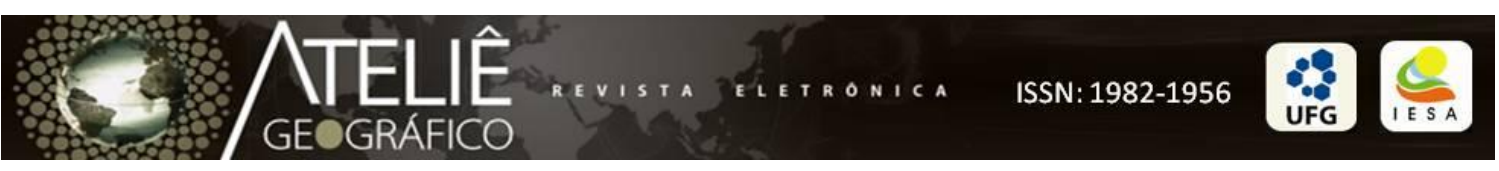

A idéia fundamental da intervenção não foi a de ensinar uma técnica aos estudantes, mas sim a de desenvolver neles a capacidade criativa no exercício da pesquisa, pois cada pessoa se apropria das imagens de uma maneira peculiar, as absorvendo e as reinterpretando. Tivemos também como meta que os alunos conhecessem e se apropriassem da linguagem fotográfica de forma crítica e contextualizada, na perspectiva da construção de uma abordagem multidimensional e plural da realidade.

A avaliação dos alunos foi realizada de forma processual e contínua e os conceitos trabalhados foram apresentados a eles de forma contextualizada, no âmbito de discussões imbricadas com linhas interpretativas da Geografia Cultural, Etnogeografia, Percepção Ambiental e Geografia das Representações.

\section{Marco Teórico-Conceitual: O Período Barroco nas Perspectivas Etnogeográfica e} Geohistórica

O Barroco é uma manifestação visual e estética (BOTELHO, REIS, 2001, p. 23)- um estilo, que corresponde direta e indiretamente a uma "estrutura mental" (MACHADO, 2003), marcado pela exuberância das formas e pela pompa litúrgicoornamental e que surge na Europa a partir do século XVII e se estende até parte do século XVIII, "correspondendo historicamente à ação contra-reformista da Igreja Católica e também à expansão colonizadora de Portugal e Espanha" (ÁVILA, GONTIJO, MACHADO, 1996, p. 131). O Barroco, segundo Ávila, Gontijo e Machado (1996, p. 5), compreenderia "um fenômeno bem amplo, vinculado tanto às lutas religiosas entre reformistas e contra-reformistas, quanto à expansão mercantilista decorrente das grandes navegações”.

Distribuído por um espaço geográfico muito amplo (compreendendo Itália, França, Espanha, Inglaterra, Alemanha, México, Brasil, dentre outros países), o estilo evoluiu diferentemente em cada lugar, assumindo dinâmica própria, do que resultaram formas e modelos particulares e originais em cada região (CIVITA, 2000). Na verdade, "mais do que um estilo artístico, o Barroco designa uma cultura entendida como uma visão de mundo constituída historicamente” (ROMEIRO, BOTELHO, 2003, p. 50). 


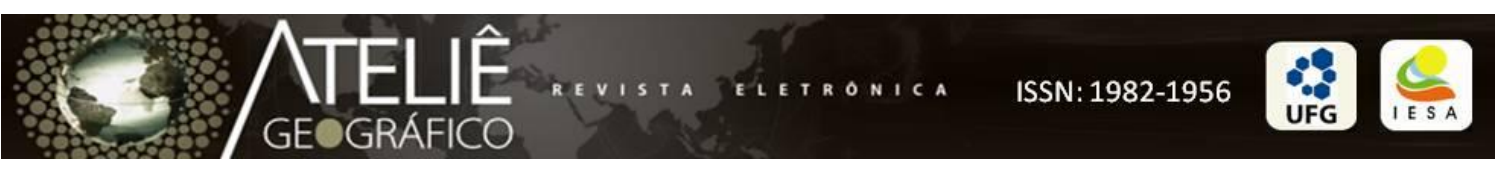

No Brasil, suas diversas manifestações culturais e artísticas aparecem a partir do século XVII, sob a influência do Barroco ibérico, mostrando a força do Estado e da Igreja Católica. Na Colônia, o Barroco do litoral, influenciado nitidamente pela Europa (BOTELHO, REIS, 2001, p. 24), desenvolveu-se principalmente na Bahia, Maranhão, Pernambuco e na zona decadente da cana-de-açúcar "marcando com suas formas o programa arquitetônico e ornamental de igrejas e conventos" (ÁVILA, GONTIJO, MACHADO, 1996, p. 131). No Rio de Janeiro, o Barroco caracterizou-se pela grande opulência dos interiores em contraste com a simplicidade das fachadas.

Nas Minas Gerais do século XVIII houve também uma influência considerável do Barroco sobre a produção cultural, assumindo neste contexto territorial, características próprias- com destaque para as obras de Antônio Francisco Lisboa (o “Aleijadinho"), de Manoel da Costa Ataíde, do Mestre Valentim e de Lobo de Mesquita. O Aleijadinho, contando com oficina própria e grande número de aprendizes, exerceu particularmente "influência na construção das características básicas das imagens mineiras, mais contidas e discretas do que as baianas e pernambucanas, porém com extraordinária força de expressão" (OLIVEIRA, PEREIRA, LUZ, 2008, p. 53). E como assinala Lima (2009, p. 24): “em mais de 50 anos de atividade, Aleijadinho percorreu vários recantos de Minas Gerais, deixando sua marca em igrejas, imagens sacras e detalhes arquitetônicos".

É por volta de 1770 que "surge uma produção regional com características próprias. Tem-se então o afastamento dos modelos portugueses e litorâneos" (CAMPOS, 2006, p. 49). E vale ressaltar que a própria origem do povo mineiro se liga aos valores associados à cultura barroca "criando uma forte relação de identidade entre eles, a ponto de se representar o estado e sua gente pelos ícones e imagens ligados ao Barroco" (CARSALADE, 2003, p. 208).

É relevante assinalar inclusive que ao erigir no estado os seus maiores ícones arquitetônicos (na Pampulha e Praça da Liberdade em Belo Horizonte, principalmente), a arquitetura modernista vai resgatar traços barrocos, procurando se sintonizar e se harmonizar com a mineiridade clássica dos tempos coloniais (DEUS, CASTRO, 2008).

Nesse território, "durante o século XVIII, a expansão dos santuários coincide com a grande corrente migratória de aventureiros portugueses e brasileiros em direção a Minas Gerais e demais regiões mineiras" (ROSENDAHL, 1997, p. 144), pois “a corrida 
do ouro mineiro, no início do século XVIII, provocou um fluxo populacional jamais visto para o interior da América Portuguesa, o qual chegou a ser denominado de "a Grande Invasão". As primeiras ondas migratórias para as minas foram tão volumosas que várias medidas restritivas tiveram que ser tomadas para coibir a transferência populacional para a região, particularmente de pessoas vindas do Reino, pois se temia seu despovoamento" (FURTADO, 2005, p. 194).

A suntuosidade decorativa do interior das igrejas inclusive "completa e acentua o aspecto monumental da arquitetura religiosa em Minas" (ÁVILA, GONTIJO, MACHADO, 1996, p. 8). E por não se restringir a um estilo artístico e designar também formas de pensamento do século XVIII, pode-se falar da existência de uma “mentalidade barroca na Minas oitocentista” (ÁVILA, GONTIJO, MACHADO, 1996, p. 10). Em Minas, a cultura barroca foi (re)inventada à luz das particularidades locais, tendo de se adaptar às condições do meio físico-geológico local (como por exemplo, a utilização do esteatito como pedra de cantaria na escultura arquitetônica), e a sua inserção no contexto de uma sociedade senhorial e escravista, por vezes ameaçada por insurreições e revoltas. Desde os seus primórdios, a história de Minas caracteriza-se por essa "efervescência mental que associa à busca obstinada da riqueza oferecida pelo solo à insubordinação e ao espírito reivindicativo, a que não falta, por outro lado, um acentuado labor artístico" (LUCAS, 1998, p. 10).

Na região de Minas Gerais, o estilo barroco assumiu aspectos distintamente originais: primeiro, sem modelos oficiais ou artesãos qualificados, durante a chegada caótica dos colonizadores da corrida em busca do ouro no início do século XVIII, e depois, alguns anos mais tarde, com o nascimento de arquitetos e artistas locais que familiarizados com a terra, eram capazes de selecionar e adaptar os elementos mais adequados a um lugar que não era a Europa. Os arquitetos de Portugal haviam descoberto o seu material ideal na madeira dourada, assim como os franceses o encontraram na pedra e os italianos, no mármore. Mas, nos morros de Minas Gerais, os materiais dos artistas se diversificaram: havia o ouro que as antigas lendas européias tinham prometido aos exploradores do Novo Mundo; havia a madeira, não o pau brasil duro, de cor marcante e caracteristicamente vermelha que dera ao país o seu nome, mas o cedro brasileiro cuja maciez se prestava ao entalhe intricado; "e havia aquele peculiar agregado compacto de talco, a mais macia de todas as pedras, usada outrora na antiga 
China e na Mesopotâmia", o esteatito ou "pedra-sabão" (MANGUEL, 2001, p. 226).

Vale ressaltar que várias regiões africanas não só possuem jazidas desse tipo litológico, o esteatito, "como registram secular utilização desse material em esculturas e objetos de uso cotidiano". Associada às outras rochas, ela "é responsável pela suavidade das curvas e pela textura refinada de vários monumentos do barroco mineiro" (PEREIRA, LICCARDO, SILVA, 2007, p. 114).

"Em Minas Gerais houve, durante os séculos XVIII e XIX, uma concentração de artífices e artistas, com mãos hábeis e talentosas, os quais ajudaram a construir o acervo arquitetônico das cidades. Dentre eles destaca-se a participação dos canteiros, artesãos que executaram inúmeras e variadas peças de cantaria" (PEREIRA, LICCARDO, SILVA, 2007, p. 91). A arte foi implantada por influência de pedreiros e canteiros portugueses e adquiriu peculiaridades devido ao uso dos tipos litológicos locais e à criatividade dos mestres, oficiais e nativos,

\footnotetext{
"marcando presença na arquitetura e ajudando a compor o belo e original acervo que caracteriza o barroco mineiro. Por se tratar de uma técnica relativamente onerosa de construção, a cantaria no século XVIII teve desenvolvimento nas vilas e cidades ligadas às riquezas do período, ou seja, a mineração do ouro e as atividades mercantis. Assim os mais completos conjuntos arquitetônicos encontram-se em Ouro Preto, Mariana, São João Del Rei, Congonhas e Tiradentes, locais de morada de governadores, bispos, nobres, autoridades militares, fazendeiros e destacados negociantes. Dentre as antigas vilas do ouro que tiveram sua arquitetura marcada pela arte canteira, Ouro Preto é a que se destaca pela quantidade e qualidade de suas obras"...
}

A cantaria ouro-pretana desenvolveu-se também com o emprego do quartzito, conhecido na época por itacolomito (VILLELA, 2003), "por ser retirado da Serra do Itacolomi. Essa rocha era considerada de excelente qualidade para o uso da cantaria" (PEREIRA, LICCARDO, SILVA, 2007, p. 23).

\section{O Barroco em Diamantina: Uma Sinergia de Cores numa Paisagem "Litificada"}

Na cidade de Diamantina, a arquitetura religiosa mostrou-se particularmente primorosa (ÁVILA, 1994). Localizado no Alto Jequitinhonha, região central do estado de Minas Gerais, o município ocupa uma área de $4.672 \mathrm{~km}^{2}$. O relevo regional é 
escarpado, de planalto irregular, marcado por afloramentos de filito e de quartzito ${ }^{3}$. Segundo Tirapelli (2000, p 215), o traçado urbano de Diamantina é resultante da compactação de três arraiais, um no vale do Tijuco, na saída para Minas Novas; outro, no arraial de baixo que saía para a Vila do Príncipe; e o arraial de cima, que fazia a conexão com o sertão baiano a oeste. Entre eles situavam-se as igrejas das Mercês, Nossa Senhora do Rosário dos Pretos e São Francisco que serviram de elo e adensamento, formando uma malha urbana desde 1771. As ligações radiais e perimetrais que se dividiram em paralelas e perpendiculares compuseram o arruamento central.

Construída em um sítio íngreme, a cidade possui traçado urbano sinuoso, formado por ruas estreitas com calçamento em pedra. O casario, definidor das ruas, não possui recuo frontal e se destaca pelo colorido vivo das esquadrias que contrasta com o branco das paredes. Nota-se aí o uso de elementos que remetem à arquitetura portuguesa influenciada pela cultura árabe, como os muxarabis e treliças nas janelas e varandas.

Encravada na inóspita Serra do Espinhaço, Diamantina é um exemplo vivo de arquitetura colonial de linhas e formas suaves, adaptada aos Trópicos. Todo o entorno da cidade caracteriza-se por grande beleza cênica, com a presença de imponentes maciços quartzíticos, quedas d'água e cavernas. Na paisagem lítica de Diamantina, Tirapelli (2000, p 213) salienta que:

os paulistas, em 1713, descobriram ouro e diamantes no Córrego CaetéMirim. Seguidos de baianos, colonizadores do norte de Portugal, intendentes diretos da Coroa e negros escravos inventaram um comportamento humano ainda hoje preservado, que transformava a vida em um processo de aventura: o garimpo que palmeia a terra.

Como se sabe, a descoberta, no início do século XVIII, de abundantes jazidas diamantíferas na inóspita região das nascentes do Rio Jequitinhonha, é que provocou o crescimento dos arraiais de garimpo de ouro anteriormente já existentes aí (e explorados com base no trabalho escravo). Em decorrência dessas descobertas, a Coroa Portuguesa implantou, em 1731, um regime especial de administração, a Demarcação Diamantina, incluindo o Arraial do Tijuco (futura cidade de Diamantina), com sede na Vila do Príncipe, hoje Serro. A Coroa Portuguesa, ávida pelos impostos provenientes das

\footnotetext{
${ }^{3}$ Rocha metamórfica muito comum no Quadrilátero Ferrífero e na Serra do Espinhaço e utilizada, como
} 
regiões auríferas descobertas no final do século XVIII investiria na procura de novos veios e, em 1729, subindo a Serra do Espinhaço, criaria na Serra dos Cristais um emaranhado de caminhos, como salienta Tirapelli, ao fundar arraiais na comarca do Serro Frio (1702). Ouro parco surge então aí, o diamante, em terras vizinhas no arraial do Tijuco, como era denominado o aglomerado dos arraiais dos Forros, Rio Grande, de Cima e de Baixo (MACHADO FILHO, 1980). A partir de 1730, ainda com uma população flutuante, o Arraial do Tijuco foi se adensando. Por meio da expansão de pequenos arraiais ao longo dos cursos d'água em direção ao núcleo administrativo do Tijuco, foi se formando o conjunto urbano de Diamantina, tendo como primeiras vias a Rua do Burgalhau, Rua Espírito Santo e o Beco das Beatas.

Em 1771, o Marquês de Pombal reforça o controle sobre as minas, instituindo o Regimento dos Terrenos Diamantinos e mantendo o Arraial do Tijuco subordinado à Comarca do Serro, situação que se altera em 1832, com sua elevação à categoria de Vila. Seis anos depois, a vila ascende à condição de cidade e passa a se chamar Diamantina. Dada à dificuldade de taxar o diamante, cujas pedras se escondem facilmente ao contrário do ouro, os mineiros foram expulsos pela Coroa que entregou então a explotação dos minérios diamantífero e aurífero a um contratador oficial da Metrópole.

O grande acontecimento da historia colonial de Diamantina foi efetivamente a descoberta de diamantes. A extração da gema tomou conta das atividades dos mineiros. Sob o signo dos diamantes, ao fluxo e refluxo de processos, desenvolveu-se a prosperidade do Tijuco, constituiu-se o ciclo especial da sua economia e plasmou-se o caráter típico do diamantinense (MACHADO FILHO, 1980).

Uma singularidade em relação às paisagens sagradas da cidade é a localização das suas igrejas. Essas, ao contrário de outros centros históricos do período barroco mineiro, integram-se ao casario, sem maior destaque na malha urbana a não ser pelos seus pequenos adros. Entre os principais exemplares, sobressaem: a Igreja Nossa do Carmo, com retábulos atribuídos a Francisco Antônio Lisboa, e o forro, com perspectiva ilusionista de autoria de José Soares de Araujo; e as Igrejas das Mercês, do Amparo, do Senhor do Bonfim, de São Francisco e do Rosário, essa última abrindo para o Largo da Cavalhada Velha, à entrada antiga da cidade.

já acentuamos, como pedra de cantaria, por exemplo, em pisos e revestimentos. 


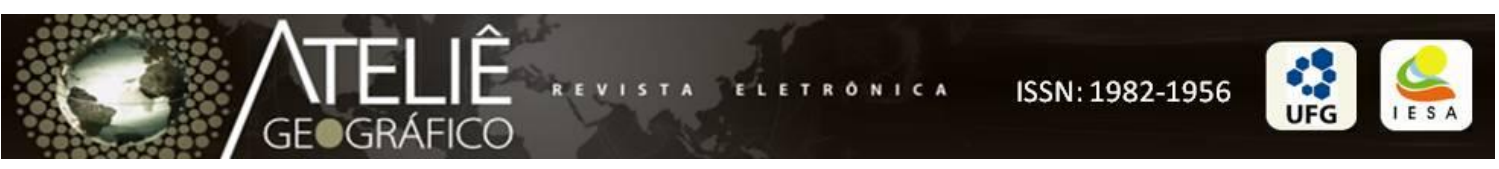

Os destaques na paisagem urbana diamantinense são as torres de seus templos religiosos; elas são pequenas, feitas de madeira e barro e alongam-se na paisagem áspera, com tons de acentuados vermelhos que enquadram os brancos das taipas e telhados à chinesa. O caso mais singular é o da igreja de Nossa Senhora do Carmo, com uma torre posterior da edificação, que com a beleza de suas talhas e pinturas interiores suscita, no turista, formas de apreensão e interpretação de uma complexa construção cultural (MENESES, 2004). O posicionamento das torres varia, acompanhado à trama urbana.

Em termos de estilos em arquitetura, a tipologia comum em Diamantina é a colonial, havendo poucos exemplos de construções neoclássicas, ecléticas ou neocoloniais. A arquitetura moderna está representada por três obras de Oscar Niemeyer, da decáda de 1950. Entre os prédios residenciais desponta o sobrado da Chica da Silva (da segunda metade do século XVIII), pela sua edificação e volumetria, mas especialmente, pelo fechamento treliçado do seu avarando lateral e amplo quintal subindo a encosta.

Outro destaque no traçado urbano diamantinense é o Largo da Cavalhada Velha, onde foi construído o Mercado Municipal e que era o local de reunião dos tropeiros e de uma grande feira regional- local de concentração de homens, mulheres, bebidas e dinheiro, o que facilitava o aconchego nas noites, as trocas afáveis de carícias e de "atos libidinosos". Na parte superior do arraial, situavam-se os currais de gado vindo da região nordeste para abastecer o Sudeste. Esta atividade, segundo o autor, foi primordial para Diamantina, após a escassez dos diamantes no século XIX (TIRAPELLI, 2000). Ainda hoje se vê ali a antiga estação da Estrada de Ferro Central do Brasil (extinta em 1973) e a atual Estação Rodoviária.

Na região de Vila do Príncipe (Serro), explorou-se ouro até 1729. Nessa data, contudo, a atividade foi proibida, pois dois anos antes haviam sido descobertas jazidas de diamantes muito mais valiosas. Declarou-se então que a extração de diamantes seria monopólio da Coroa e que todas as concessões de garimpo do ouro estavam canceladas. A formação do município está intrinsecamente ligada à explotação do ouro e do diamante (BRITO, 2009). A ocupação inicial do território se deu com Jerônimo Gouveia, que, seguindo o curso do Rio Jequitinhonha encontrou, nas confluências do Rio Pururuca e Rio Grande, uma grande quantidade de ouro. Por volta de 1722, 
começou o surgimento do povoado, sempre seguindo as margens dos rios que eram garimpados.

Nos arredores de Diamantina, ao longo do Rio Jequitinhonha, ainda encontramos nos dias de hoje, homens morenos faiscando nos leitos dos rios e cursos d'água que lembram as sugestivas pinturas e desenhos elaborados nos tempos coloniais ou imperiais por cronistas e viajantes como Eschwege (1996, 2002), Debret (1993, 2006), Rugendas (1998), Spix \& Martius (SPIX, 1981) e Saint Hilaire (2000, 2004). No distrito de Mendanha, $80 \%$ da população masculina se dedicam ao garimpo. Mas hoje, a exploração dos diamantes e do ouro está em xeque, e em declínio, na região de Diamantina. As grandes empresas de mineração já levaram o que havia de melhor e atualmente existe também muita fiscalização dos negócios por parte dos órgãos ambientais e Polícia Federal. Mas é notável que, passados mais de trezentos anos do início da grande corrida do ouro, o sonho de riqueza ainda permaneça vivo nos sertões das Minas Gerais. No distrito de Sopa, distante apenas $22 \mathrm{~km}$ de Diamantina e localizado no Vale do Jequitinhonha, por exemplo, vários garimpeiros continuam o paciente ofício de separar o cascalho à procura do ouro com a bateia; e o diamante, com a peneira.

\section{O Sagrado e o Profano na Minas Colonial Barroca e Suas Reverberações no Brasil Contemporâneo}

A cultura barroca mineira é um mesclado a um só tempo, do sagrado e do profano. Estes espaços sagrado e profano admitem três dimensões distintas: a dimensão econômica (compreendendo os bens simbólicos, os mercados e as redes), a dimensão política (compreendendo a religião, o território, a territorialidade, a religião civil, a sacralidade e a identidade) e a dimensão do Lugar (compreendendo a difusão da Fé, a comunidade, a identidade religiosa, a hierópolis, a percepção, a vivência, o simbolismo, a paisagem religiosa e a região cultural (ROSENDAHL, 2003), no qual a morte e as preocupações com a salvação da alma ocupam um lugar central, convivendo, entretanto, de forma harmoniosa com as celebrações e festividades- o espaço privilegiado de toda a sociabilidade (ROMEIRO, BOTELHO, 2003). 


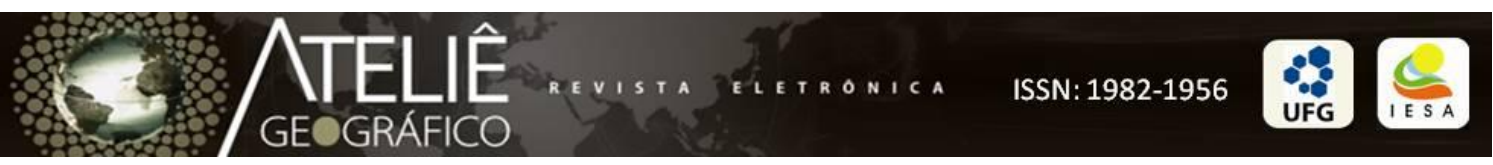

A religiosidade mineira se manifesta por meio de um conjunto de práticas de devoção, tais como o culto aos santos, às almas do Purgatório e a crença em milagres. E no modelo festivo barroco do catolicismo colonial português nunca foram muito claras, de fato, as fronteiras entre o sagrado e o profano:

\begin{abstract}
a bebida, ao lado da comida, fazia parte integrante das festas, tanto religiosas quanto profanas, das comemorações, das reuniões. Não havia festa sem seu consumo. Mesmo a embriaguez parecia natural e permitida nessas ocasiões, se houvesse uma boa intenção, como o desejo de homenagear os santos e os valorizar. Ao menos, essa era uma crença bastante divulgada. A bebida servia como uma real homenagem e mesmo alguns excessos pareciam dignos de perdão (SCARANO, 2001, p. 478).
\end{abstract}

$\mathrm{Na}$ Minas oitocentista,

a sociedade e a religião não constituíam instâncias separadas. Uma festa de cunho religioso podia ao mesmo tempo exaltar o Santíssimo Sacramento, o novo bispado, e por meio dele, o monarca cristão, que a tudo precedia, assim como seus vassalos obedientes e piedosos, de quem se esperava tanto o zelo da coisa pública quanto a observância da fé. Se a festa expressa a religiosidade da população mineira, e quase sempre exacerbada, ela celebra também o apogeu da mineração e tenta estancar os males advindos de sua decadência (SOUZA, 2001, p. 187).

As celebrações cívicas eram anunciadas por cortejos de mascarados ao som de músicas e, mesmo nas festas religiosas, as procissões eram seguidas de espetáculos pirotécnicos, encenações teatrais, bailes, jogos de destreza a cavalo ou corridas de touros. Ao revisitarmos a nossa história religiosa, católica e centro da própria vida dos séculos XVII e XVIII, percebemos que foi ali que nasceu esse universo sagrado e profano que faz a nossa cultura tão original e singular.

Em sua abordagem sobre as festas do apogeu minerador, Souza (2001) registra como nessas ocasiões, tudo reluzia nos enfeites de ouro e prata, tudo faiscava em pedras preciosas, traduzindo a euforia da sociedade mineradora, opulenta, desigual e arrivista. "Momento privilegiado da cultura e sociabilidades barrocas, a festa religiosa era um ritual público, que tanto servia para reforçar os laços de solidariedade quanto refletir os valores sociais que pautavam o ordenamento social". A um só tempo profana e religiosa, a festa divulgava as normas a serem seguidas, hierarquizava os lugares sociais, distinguindo uns e excluindo outros. "Espaço de lazer e de afrouxamento das 


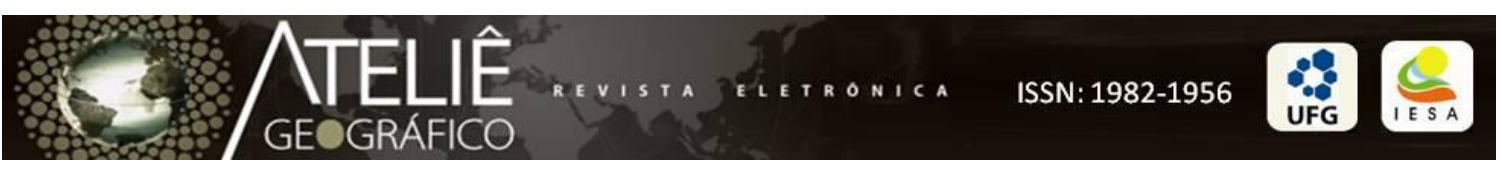

obrigações sociais, ela também impunha a obediência à Igreja e ao Estado, destacando a proximidade entre a população e o sagrado" (ROMEIRO, BOTELHO, 2003, p. 142).

Numa região de fronteira ${ }^{4}$ aberta, "as festas barrocas ritualizaram as diferenças e, ao mesmo tempo, desempenharam papel central na neutralização momentânea de conflitos e de clivagens sociais, produzindo, bem ao gosto do barroco, a ilusão que a realidade dura era um sonho bom" (SOUZA, 2001, p. 195). Tais conflitos atingiam seu ápice nos violentos e permanentes enfrentamentos entre conquistadores e as sociedades indígenas ou núcleos quilombolas (DEUS, NOGUEIRA, FANTINEL, 1998).

Pode se inclusive se levantar a hipótese de que o Carnaval de hoje, dos grandes desfiles das escolas de samba tenha se inspirado nos desfiles comemorativos sagrados e profanos, do período colonial barroco (ÁVILA, GONTIJO, MACHADO, 1996, p. 7). A história registrou ao longo do século XVIII, pelo menos três grandes cortejos barrocos: a procissão do Triunfo Eucarístico na antiga Vila Rica (hoje, Ouro Preto), e outras dois incidentes respectivamente no Rio de Janeiro e na Bahia (em Santo Amaro da Purificação).

Os brasileiros vêm misturando o Sagrado e o Profano há muitos anos, num admirável processo de sincretismo. Os detalhes que recobrem as paredes e o mobiliário que adornam as imagens de nossas igrejas têm, aliás, muito a ver com a maneira atual com que o nosso povo usa as suas fantasias e máscaras, seja quando pinta os corpos quase nus no Carnaval, seja quando veste roupas de preceito nas festas religiosas.

E a arte barroca mineira concebia a vida com um grande e suntuoso espetáculo. Podemos perceber nesse estilo de arte, certa ênfase na exaltação da novidade, do exótico e do extravagante, bem como na reinvenção e apropriação de várias culturas como a africana, indígena, chinesa e européia (em Diamantina/MG, como já reportamos, são localizadas nítidas influências mouriscas na arquitetura - ROMEIRO, BOTELHO, 2003). Para Borges (2005), o sincretismo deve ser visualizado como um processo dinâmico, envolvendo uma relação intelectual e emocional dos agentes. Vale ressaltar que, no interior da Igreja São Francisco de Assis, em Ouro Preto, as imagens religiosas,

\footnotetext{
${ }^{4} \mathrm{O}$ termo fronteira, clássico conceito geográfico que etimologicamente deriva do vocábulo "front" (o "front" da guerra), é aplicado aqui em seu sentido mais amplo, de fronteira de expansão econômica, demográfica etc. de uma sociedade, civilização ou cultura sobre um território "virgem", inexplorado, como aconteceu no Brasil Colônia na região das Minas, e no período mais recente, na região amazônica (BECKER, 2005). Vale ressaltar, a propósito, que a realidade sociocultural e política das áreas de
} 
embora cristãs, também se prestam a uma leitura segundo a tradição africana... Assim a Nossa Senhora do Rosário é também Yemanjá, a deusa africana do mar... "Os cascos de tartaruga representados nos baixos relevos possuem significados próprios e específicos nos ritos de iniciação dos escravos. Na Igreja de São Francisco de Assis as imagens podem ser européias, mas a articulação, as correntes ocultas de significado pertencem definitivamente às tradições negras da África [...]”. (MANGUEL, 2001, p. 239-240). Como testemunhos deste universo multicultural merecem serem destacadas as obras arquitetônicas e artísticas das igrejas de Nossa Senhora do Rosário, em Ouro Preto, e de Nossa Senhora do Ó, em Sabará.

Vale ressaltar ainda que, como registramos anteriormente, alguns mulatos como o "Aleijadinho" e Mestre Ataíde destacaram-se significativamente no contexto histórico e sociocultural do Barroco (PIANZOLA, 1975), brilhando principalmente nas artes plásticas e na música. Manguel (2001, p. 238), destaca que os escravos africanos (como o Maurício, do Aleijadinho), que nos países de origem (Nigéria, Benin, Congo, Angola, Moçambique, Guiné) "tinham sido escultores, fabricantes de máscaras, ferreiros e arquitetos, trouxeram as suas habilidades e talentos através do mar até o Brasil".

Já "as manifestações artísticas que apresentam forte influência oriental" (ROMEIRO, BOTELHO, 2003, p. 77), ficaram classicamente conhecidas como as "chinesices" do barroco mineiro. "Nas Minas, as chinesices aparecem a partir do século XVIII e têm na pintura a sua principal expressão [...]. A presença oriental estava incorporada ao cotidiano das Minas, por meio dos mais diversos utensílios [...] e dos motivos e temas das artes visuais, resultantes da circulação de múltiplas culturas no âmbito do universo ultramarino português" (ROMEIRO, BOTELHO, 2003, p. 78). As “chinesices" são registradas em muitas igrejas mineiras do período barroco, sendo as mais conhecidas "as da Matriz de Nossa Senhora da Conceição de Sabará, da Capela de Nossa Senhora do Ó de Sabará e da Matriz de Nossa Senhora da Conceição de Catas Altas. Nessas igrejas, as chinesices introduzem uma nota profana, característica do Barroco que une o sagrado e o profano" (ROMEIRO, BOTELHO, 2003, p. 77).

No Barroco Mineiro, muitos foram os fatores que contribuíram para a criação de uma cultura autônoma e de um estilo regional próprio, dentre os quais podemos destacar o contato com técnicas artísticas tanto de origem culta como popular, a atuação decisiva

"fronteira" tem um caráter acentuadamente contraditório e dinâmico (DEUS, BARBOSA, TUBALDINI, 
de irmandades e confrarias (associações voluntárias com caráter de auxílio mútuo/ assistência social). De acordo com Botelho \& Reis (2001, p. 47), no Brasil colonial foram de fato "criadas associações nos moldes das confrarias, denominadas Irmandades".

E contribuíram para a constituição de uma sociedade diversificada nas Minas Gerais as necessidades de uma religiosidade pouco ortodoxa, a distância dos centros artísticos litorâneos, o afluxo de mestres de obras e oficiais provenientes de Portugal, a circulação de gravuras da Europa, e a inexistência aqui de escolas ou de tradições artísticas estabelecidas.

Nas Minas, foram os leigos os responsáveis pela implantação do catolicismo e não os religiosos, por meio de Irmandades que, num primeiro momento agregavam senhores e escravos. Competiam a tais associações os encargos com o estabelecimento e a manutenção do culto religioso, razão pela qual a Coroa estimulava o seu aparecimento (ROMEIRO, BOTELHO, 2003, p. 181).

As Irmandades representavam a realidade racial e ideológica da sociedade escravista (CAMPOS, 2007). Havia associações de negros, de mulatos e de brancos. "As Irmandades muito contribuíram com a Metrópole no processo de colonização do Brasil, ajudando a diminuir as tensões sociais (conflitos entre as várias camadas da população), pois representavam um espaço onde as pessoas se reuniam, cantavam e aliviavam suas tristezas e sofrimentos.

No caso dos escravos, por exemplo, "as Irmandades abriam uma oportunidade para as manifestações culturais africanas, como o Reisado e o Congado" (BOTELHO, REIS, p. 101). "Os rituais do Reinado de Nossa Senhora do Rosário, ou Congado, constituem uma das mais importantes expressões da religiosidade e da cultura afrobrasileira presentes em Minas Gerais. A cada ano, sob o comando dos tambores, das caixas e demais instrumentos, milhares de pessoas, das pequenas vilas à capital, cantam e dançam sua fé, prestando homenagens a Nossa Senhora do Rosário, aos seus antepassados e aos santos de sua devoção, sobretudo dos negros, Santa Ifigênia e São Benedito, reatualizando e recriando a memória ancestral” (LUCAS, 2002, p. 17).

Essas expressões culturais desenvolveram-se "no interior do sistema escravista brasileiro, resultando do violento processo de imposição cultural sofrido pelos negros. 
Como decorrência dos contatos culturais, os negros reelaboraram valores alheios à sua concepção de mundo, reinterpretando, assim, o catolicismo, por meio de sua própria cosmovisão. Nos rituais do Congado, portanto, estão presentes valores e saberes africanos, principalmente vinculados às culturas bantu; os quais, trazidos para o Novo Mundo, sobreviveram às imposições da cultura dominante, com ela se mesclaram, e se transformaram continuamente em sua trajetória brasileira" (LUCAS, 2002, p. 17-18). Os Congados evidenciariam o prestígio do antigo reino africano do Congo no imaginário popular brasileiro, segundo SERRANO e WALDMAN (2007).

O barroco mineiro captou o universo sensível da profundeza da alma humana e a sensualidade de madonas, santos e anjos (expressa na solidez dos corpos, nos trejeitos humanos, no sorriso matreiro de arcanjos e querubins presentes nas pinturas LATERZA, VIEGAS, 2003), que revela a alegria de viver, a vontade de celebrar a dimensão mais profana da existência, tanto no sentido imediato das paixões, quanto no sentido profundo da experiência da plenitude.

Essa representação da dimensão mais profana da realidade acoplada ao sagrado, mas impregnada de signos e fenótipos afro, pode ser bem exemplificada pelo teto da nave da Igreja de São Francisco de Assis em Ouro Preto (Ataíde), onde uma madona de cabelos crespos, nariz largo, lábios carnudos, seios fartos (revelados por um decote insinuante, inusitado em uma figura sagrada!), é rodeada por anjos também com traços mestiços! São características singulares que podem ser atribuídas à genialidade dos artistas de origem afro-brasileira. Paradoxalmente, o elemento afro, fisicamente segregado e ausente do interior das igrejas àquela época, marcava sua presença e demarcava assim seu espaço, no plano do simbólico, exercendo de forma efetiva e original, seu protagonismo, nesse contexto histórico particular.

Outro trabalho de pintura a óleo sobre tela de grande importância no período compreendido entre o século XVIII e início do século XIX, de autoria de Manoel da Costa Ataíde, com aspectos subjacentes de "descontração" e de "informalidade", corresponde à "Santa Ceia” do colégio confessional do Caraça (Santa Bárbara/ MG) em que se observa uma flagrante contradição com os rígidos preceitos do catolicismo de outrora quanto à restrição de consumo de carne durante a quaresma. Na pintura, com efeito, se percebe que os apóstolos tinham consumido um cordeiro (cujos ossos estão sobre o centro da mesa). Há ainda a representação de três mulheres que servem os 
apóstolos à mesa, sendo duas de corpo inteiro. Destas, uma está de costas e traz uma garrafa na mão esquerda, enquanto levanta a direita ao conversar com um homem (seria uma serviçal?). A outra vem da cozinha trazendo entre as mãos, uma travessa com um grande pão, enquanto recebe carícias no ombro direito de outro homem. A terceira, com a cabeça recoberta por um manto, tem o corpo ocultado pela anterior. Posiciona-se sob a porta da cozinha, mostrando somente o rosto (CAMPOS, 2005, p. 239). Esse rosto é de uma crioula ou mulata. "Talvez o pintor tenha querido retratar a importância do negro em Minas. Seu contemporâneo Aleijadinho e muitos de seus auxiliares eram mulatos" (ZICO, 2003, p. 222). Em oposição à tradição pictórica européia de certa austeridade nas representações da Santa Ceia, esta cena dá assim "um toque de graça profana a uma passagem tão tocante da vida de Cristo" (COELHO, 2005, p. 98).

\section{Considerações Finais: O Barroco e o Seu Papel na Definição e Configuração das Paisagens Culturais Mineiras}

Para Almeida "a paisagem é uma construção, um produto da apropriação e da transformação do ambiente em cultura" (ALMEIDA, 2008, p. 47). Enquanto que para Corrêa, "a paisagem é, de um lado, o resultado de uma dada cultura que a modelou e, de outro, constitui-se em uma matriz cultural" (CORRÊA, 2001, p. 290). Roberto Lobato Corrêa aliás caracteriza a paisagem como "uma vitrine permanente de todo o saber, expressando a cultura em seus diversos aspectos, possuindo uma faceta funcional e outra simbólica". Já segundo Corrêa e Rosendahl (2004, p.8):

\footnotetext{
a paisagem foi descrita pelos viajantes e geógrafos do passado, considerada como interface de processos naturais e sociais, e analisada a partir de representações cartográficas e um olhar geográfico. As leituras sobre a paisagem são inúmeras, incluindo uma leitura funcional, outra na perspectiva arqueológica e outra segundo uma abordagem cultural, em relação à qual foi notável a contribuição de Carl Sauer.
}

E de acordo com Claval (2004, p.71) a paisagem como indício diz muito sobre a sociedade que a produziu. Gandy $(2004,86)$, por sua vez, enfatiza que a paisagem é um fator determinante do caráter social e cultural das sociedades.

Entende-se como paisagem cultural um conjunto de formas materiais dispostas e articuladas entre si no espaço. Como observa Meneses (2004, p. 26) “é provável que, se 
fizermos uma pesquisa em qualquer cidade do mundo, veremos que a população urbana guarda carinho especial com lugares que quer preservar e que busca vivenciar". E Cosgrove (1998), um dos maiores expoentes das linhas interpretativas da "escola anglosaxônica" da Geografia Cultural contemporânea (DEUS, 2005), destaca, por sua vez, que "há muito trabalho interessante a ser realizado sobre paisagens do passado e seus significados contemporâneos, e é um bom ponto de partida sua recriação em museus e parques temáticos".

É importante destacar o caráter dialético e evolutivo que a paisagem cultural pode exibir (TORELLY, 2008); e vale assinalar ainda que o conceito "abarca também as ideias de pertencimento, significado, valor e singularidade do lugar“" (SANTILLI, 2009). Pois como registra Torelly (2008, p. 240-241),

\footnotetext{
"ao vislumbrarmos uma paisagem, nossos sentidos como a visão, a audição e o olfato, são estimulados e as sensações são imediatamente processadas por nosso intelecto, que se utiliza de todo o nosso aparato cognitivo, que acumulamos desde o nascimento, para atribuir valores subjetivos e objetivos e formar representações".
}

A religiosidade católica, o fascínio pelo ouro, o desejo de afirmação e autonomia unidas num só sentimento, explicam nos plano psicológico e social, a criação da arte em Minas e de uma singular paisagem barroca.

Assumimos aqui, como hipótese de trabalho, que esta paisagem cultural barroca das Minas do século XVIII, composta por vários elementos simbólicos que incluem a arquitetura civil e religiosa, a história cultural, as manifestações artísticas, os rituais sagrados e profanos, o sincretismo religioso, etc. constitui um exemplo de "paisagem cultural subordinada e residual" (na perspectiva de Denis Cosgrove), pois como sinalizam autores como Ávila, Gontijo e Machado (1996, p. 9), cidades mineiras como Ouro Preto, Mariana, Diamantina, Tiradentes, Serro, São João Del Rei ou Sabará, dentre outras, "ostentam ainda hoje, quase intocada, a paisagem própria do século XVIII". Em Ouro Preto, por exemplo, o traçado urbano colonial mantém-se intacto e as arquiteturas religiosa e civil mais expressivas, bem como as suas obras de arte, encontram-se preservadas. 
Poderíamos incluir nesse circuito das cidades do período barroco (visualizadas como paisagens culturais residuais, ou do passado), também a hierópolis ${ }^{5}$ (conceito difundido pela Geografia das Religiões), de Congonhas do Campo (onde se situa o local de peregrinação da época barroca conhecido como "Santuário do Senhor Bom Jesus de Matosinhos do Arraial das Congonhas do Campo", e cuja criação foi inspirada "no exemplo da igreja de Bom Jesus, em Braga, Portugal” (MANGUEL, 2001, p. 233).

As mixagens interculturais constituiriam importantes códigos para compreender essas paisagens culturais particulares (AUBRÉE, 2000). Poderíamos inclusive identificar como um dos vetores mais contemporâneos e visíveis dessas paisagens, o "saber fazer" das comunidades rurais locais de distritos de Ouro Preto- envolvidas com o artesanato em pedra-sabão (LIMA, 2009), com a fabricação de cachaça em alambiques tradicionais e com a produção de doces- como a "goiabada-cascão" e marmelada-, ou com a fabricação de farinha de mandioca e fubá em moinhos d'água. E como aponta Simão (2001), "o passado e suas referências marcadas no território, as manifestações culturais tradicionais, repassadas de geração em geração, as formas de fazer (objetos, alimentos, festas), voltam, na atualidade, a ser valorizadas".

Amorim Filho (1999, p. 143) visualiza de forma bastante sugestiva essas representativas paisagens mineiras, para ele geradoras na população regional, de fortes relações e sentimentos topofílicos (TUAN, 1980), ao demarcar que:

\begin{abstract}
Minas Gerais possui o maior percentual de bens tombados no Brasil desde unidades espaciais de considerável dimensão, como é o caso de cidades inteiras (Ouro Preto, Mariana, Diamantina, por exemplo)... Esses bens tombados possuem valores que caracterizam a mineiridade, além de serem portadores de algumas das mais caras aspirações mineiras e nacionais. São, por outro lado, marcos de uma civilização que trazia para as montanhas de Minas simultaneamente, os valores paradoxais da busca da riqueza, da religião, da arte e da espiritualidade.
\end{abstract}

Para Funari e Pelegrini (2006, p. 29), a valorização do patrimônio cultural e a necessidade de reabilitar os centros históricos, na atualidade, "constituem premissas básicas dos debates sobre o desenvolvimento sustentável das cidades latino-americanas, pois esses centros representam a síntese da diversidade que caracteriza a própria cidade”. E vale ressaltar que o investimento na dimensão cultural corresponde hoje a um

\footnotetext{
${ }^{5}$ Define-se hierópolis ou cidades-santuário como "todos aqueles lugares considerados sagrados por uma dada população local, regional ou nacional” (ROSENDAHL, 2003, p. 206).
} 
dos critérios essenciais para se definir ou se caracterizar a sustentabilidade urbana de metrópoles, centros médios e/ou pequenas cidades.

\section{Referências Bibliográficas}

ALMEIDA, Maria Geralda. Diversidades Paisagísticas e Identidades Territoriais e Culturais no Brasil Sertanejo. In: ALMEIDA, Maria Geralda; CHAVEIRO, Eguimar Felíceo; BRAGA, Helaine Costa. Geografia e Cultura: Os Lugares da Vida e a Vida dos Lugares. Goiânia: Editora Vieira, 2008, p. 47-74.

AMORIM FILHO, Oswaldo Bueno. Topofilia, Topofobia e Topocídio em Minas Gerais. In: DEL RIO, Vicente, OLIVEIRA, Lívia. Percepção Ambiental: A Experiência Brasileira. São Carlos (SP): EdUFSCAR/Studio Nobel, 1999, p. 139-152.

AUBRÉE, Marion. L'Apport Africain Dans la Culture Nationale Brésilienne. Hérodote, Paris, n. 98, p. 148-160, 2000.

ÁVILA, Affonso. Minas Gerais: Monumentos Históricos e Artísticos - Circuito do Diamante. Belo Horizonte: Fundação João Pinheiro, 1994, 522 p.

ÁVILA, Affonso; GONTIJO, João Marcos Machado; MACHADO, Reinaldo Guedes. Barroco Mineiro: Glossário de Arquitetura e Ornamentação. Belo Horizonte: Fundação João Pinheiro, 1996, 232 p.

BECKER, Bertha Koiffman. Amazônia: Nova Geografia, Nova Política Regional e Nova Escala de Ação. In: COY, Martin; KOHLHEPP, Gerd. Amazônia SustentávelDesenvolvimento Sustentável Entre Políticas Públicas, Estratégias Inovadoras e Experiências Locais. Rio de Janeiro: Editora Garamond, 2005, p. 23-44.

BORGES, Célia Maia. Escravos e Libertos nas Irmandades do Rosário - Devoção e Solidariedade em Minas Gerais - Séculos XVIII e XIX. Juiz de Fora (MG): Editora UFJF, 2005, $252 \mathrm{p}$.

BOTELHO, Ângela Viana; REIS, Liana Maria. Dicionário Histórico- Brasil: Colônia e Império. Belo Horizonte: Botelho, A. V. \& REIS, L. M., 2001, 320 p.

BRITO, Octávio Elíseo Alves. Um Olhar Sobre a Paisagem Cultural de Minas: Ouro, Diamante, Rochas Para Construção. In: COSTA, Antônio Gilberto. Rochas e Histórias do Patrimônio Cultural do Brasil e de Minas. Rio de Janeiro: Editora Bem-Te-Vi, 2009 , p. 34-45.

CAMPOS, Adalgisa Arantes. A Pintura de Manoel da Costa Ataíde: Notas Sobre Suas Fontes, Aspectos Iconográficos e Estilísticos. In: CAMPOS, Adalgisa Arantes. Manoel da Costa Ataíde: Aspectos Históricos, Estilísticos, Iconográficos e Técnicos. Belo Horizonte: Editora C/Arte, 2005, p. 217-250 
CAMPOS, Adalgisa Arantes. Escatologia, Iconografia e Práticas Funerárias no Barroco das Geraes. In: RESENDE, Maria Efigênia Laje; VILLALTA, Luiz Carlos - As Minas Setecentistas II. Belo Horizonte: Autêntica Editora/Companhia do Tempo, 2007, p. $383-425$.

CAMPOS, Adalgisa Arantes. Introdução ao Barroco Mineiro: Cultura Barroca e Manifestações do Rococó em Minas Gerais. Belo Horizonte: Crisálida Editora, 2006, 80 p.

CARSALADE, Flávio. Itinerário dos Órgãos Estaduais de Preservação do Patrimônio Histórico: O Caso do IEPHA/MG. In: CASTRIOTA, Leonardo Barci. Urbanização Brasileira: Redescobertas. Belo Horizonte: Editora C/Arte, 2003, p. 207- 219.

CASTRO, Henrique Moreira; DEUS, José Antônio Souza. Um Olhar Etnogeográfico Sobre as Paisagens Culturais Barrocas do Hinterland Brasileiro na(s) Minas Oitocentista(s). In: ENCUENTRO DE GEÓGRAFOS DE AMERICA LATINA, 12, 2009, Montevidéu, Anais... Montevidéu/Uruguay, 2009, p. 1-15.

CIVITA, Victor. Os Grandes Artistas - Barroco e Rococó. São Paulo: Editora Nova Cultural, 2000, 360 p.

CLAVAL, Paul. A Paisagem do Geógrafo. IN: CORRÊA, Roberto Lobato; ROSENDAHL, Zeny. Paisagens, Textos e Identidade. Rio de Janeiro: EDUERJ, 2004, p. 13-74.

COELHO, Beatriz. Restaurações de Pinturas do Mestre Ataíde. In: CAMPOS, Adalgisa Arantes. Manoel da Costa Ataíde: Aspectos Históricos, Estilísticos, Iconográficos e Técnicos. Belo Horizonte: Editora C/Arte, 2005, p. 83-110.

CORRÊA, Roberto Lobato. A Dimensão Cultural do Espaço: Alguns Temas. In: CORRÊA, Roberto Lobato. Trajetórias Geográficas. 2 Ed. Rio de Janeiro: Bertrand Brasil, 2001, 304 p.

CORRÊA, Roberto Lobato; ROSENDAHL, Zeny. Paisagens, Textos e Identidade: Uma Apresentação. IN: CORREAA, Roberto Lobato, ROSENDAHL, Zeny. Paisagens, Textos e Identidade. Rio de Janeiro: EDUERJ, 2004, p. 7-11.

COSGROVE, Denis. A Geografia Está Em Toda a Parte: Cultura e Simbolismo nas Paisagens Humanas. In: CORREAA, Roberto Lobato, ROSENDAHL, Zeny. Paisagem, Tempo e Cultura. Rio de Janeiro: EdUERJ, 1998, p. 92-123.

DEBRET, Jean Baptiste. Caderno de Viagem. Rio de Janeiro: Editora Sextante Artes, 2006, 96 p.

DEBRET, Jean Baptiste. O Brasil de Debret. Belo Horizonte: Villa Rica Editoras Reunidas, 1993, 29 p.

DEUS, José Antônio Souza. Geografia Cultural do Brasil/Etnogeografia. Belo Horizonte, Editora UFMG, 2010, 134 p. 
DEUS, José Antônio Souza. Linhas Interpretativas e Debates Atuais no Âmbito da Geografia Cultural, Universal e Brasileira. Belo Horizonte, Caderno de Geografia, v. 15 , n. 25, p. $45-59,2^{\circ}$. sem. 2005.

DEUS, José Antônio Souza; CASTRO, Henrique Moreira. Oscar Niemeyer - Dream And Innovation Architect's Works of Art and Inter-Transdisciplinary Inclusion Teaching Practices Developed in Belo Horizonte Metropolitan Region. Goiânia, Ateliê Geográfico, v. 2, n. 4, p. 138-155, ago. 2008.

DEUS, José Antônio Souza; NOGUEIRA, Marly; FANTINEL, Lúcia Maria. Índios e Quilombolas nas Regiões de Antiga Mineração no Brasil: A Dimensão Geohistórica e a Percepção do Espaço, Caderno de Ciências Humanas, Belo Horizonte, v. 6, n. 1, p. 68-76, out. 1998.

DEUS, José Antônio Souza; BARBOSA, Liliane de Deus; TUBALDINI, Maria

Aparecida dos Santos. Realidades Culturais na Organização do Espaço: Lutas Pela Terra e Emergência de Identidades Coletivas no Contexto da Amazônia Sul-Americana e Brasileira. Geografia, Rio Claro (SP), v. 36 (Número Especial), p. 157-167, set. 2011.

ESCHWEGE, Wilhelm Ludwig von. Brasil, Novo Mundo. Tradução de Domício F. Murta. Belo Horizonte: Fundação João Pinheiro, 1996, 276 p. Original Alemão.

ESCHWEGE, Ludwig von. Jornal do Brasil - 1811/ 1817: Relatos Diversos do Brasil Coletados Durante Expedições Científicas. Tradução de Friedrich E. Renger, Tarcísia L. Ribeiro e Günter Augustín. Belo Horizonte: Fundação João Pinheiro, 2002, 408 p. Original Alemão.

FUNARI, Pedro Paulo; PELEGRINI, Sandra de Cássia Araújo. Patrimônio Histórico e Cultural. Rio de Janeiro: Jorge Zahar Editor, 2006, 72 p.

FURTADO, Junia Ferreira. Transitar na Estrada Real - O Cotidiano dos Caminhos. In: COSTA, Antônio Gilberto. Os Caminhos do Ouro e a Estrada Real. Belo Horizonte: Editora UFMG/Kapa Editorial, 2005, p. 192-205.

GANDY, Matthew. Paisagem, Estéticas e Ideologia. In: CORRÊA, Roberto Lobato; ROSENDAHL, Zeny. Paisagens, Textos e Identidade. Rio de Janeiro: EDUERJ, 2004, p. 75-90.

LATERZA, Moacyr; VIEGAS, Sônia. Alegria no Aleijadinho. In: MENDES, Nancy Maria. O Barroco Mineiro em Textos. Belo Horizonte: Autêntica Editora, 2003, p. 113-116.

LIMA, Vivi Fernandes. As Marcas de Aleijadinho. Revista de História da Biblioteca Nacional, Rio de Janeiro, v. 5, n. 51, p. 16-26, dez. 2009.

LUCAS, Fábio. Luzes e Trevas - Minas Gerais no Século XVIII. Belo Horizonte: Editora UFMG, 1998, 184 p. 
LUCAS, Glaura. Os Sons do Rosário: O Congado Mineiro dos Arturos e Jatobá. Belo Horizonte: Editora UFMG, 2002, 360 p.

MACHADO, Lourival Gomes. Barroco Mineiro. São Paulo, Editora Perspectiva, 2003, 439 p.

MACHADO FILHO, Aires da Mata. Arraial do Tijuco - Cidade de Diamantina. 3 Ed. Belo Horizonte: Editora Itatiaia/EdUSP, 1980, 306 p.

MANGUEL, Alberto. Lendo Imagens: Uma História de Amor e Ódio. Tradução de Rubens Figueiredo, Rosaura Eichemberg e Cláudia Strauch. São Paulo: Companhia das Letras, 2003, 358 p. Original Inglês.

MENESES, José Newton Coelho. História \& Turismo Cultural. Belo Horizonte: Autêntica Editora, 2004, 128 p.

OLIVEIRA, Myriam Andrade Ribeiro; PEREIRA, Sônia Gomes; LUZ, Ângela Ancora. História da Arte no Brasil: Textos de Síntese. Rio de Janeiro: Editora UFRJ, 2008, $236 \mathrm{p}$.

PEREIRA, Carlos Alberto, LICCARDO, Antonio, SILVA, Fabiano Gomes. A Arte da Cantaria. Belo Horizonte: Editora C/Arte, 2007, 119 p.

PIANZOLA, Maurice. Brasil Barroco. Tradução de J. A. Neves. Rio de Janeiro: Distribuidora Record, 1975. 181 p.Original Francês.

ROMEIRO, Adriana; BOTELHO, Ângela Viana. Dicionário Histórico das Minas Gerais. Belo Horizonte: Autêntica Editora, 2003, 320 p.

ROSENDAHL, Zeny. Espaço, Cultura e Religião: Dimensões de Análise. In: CORRÊA, Roberto Lobato, ROSENDAHL, Zeny. Introdução à Geografia Cultural. Rio de Janeiro: Bertrand Brasil, 2003, p. 187-224.

ROSENDAHL, Zeny. O Sagrado e o Espaço. In: CASTRO, Iná Elias, GOMES, Paulo César da Costa, CORRÊA, Roberto Lobato - Explorações Geográficas: Percursos no Fim de Século. Rio de Janeiro: Bertrand Brasil, 1997, p. 119-153.

RUGENDAS, Johan Moritz. Viagem Pitoresca Através do Brasil. Tradução de Sérgio Milliet. Belo Horizonte: Editora Itatiaia,1998, 166 p.

SANTILLI, Juliana. Agrobiodiversidade e Direitos dos Agricultores. São Paulo: Editora Peirópolis, 2009, 519 p.

SCARANO, Julita. Bebidas Alcoólicas e Sociedade Colonial. In: JANCSÓ, István; KANTOR, Iris. Festa: Cultura \& Sociabilidade na América Portuguesa. São Paulo: Editora Hucitec/EdUSP/Imprensa Oficial do Estado de São Paulo/FAPESP, 2001, p. 467-486.

SAINT HILAIRE, Auguste. Viagem Pelas Províncias do Rio de Janeiro e Minas Gerais. Tradução de Vivaldi Moreira. Belo Horizonte: Editora Itatiaia, 2000, 378 p. 
SAINT HILAIRE, Auguste. Viagem Pelo Distrito dos Diamantes e Litoral do Brasil.

2 Ed. Tradução de Leonam A. Penna. Belo Horizonte: Editora Itatiaia, 2004, 233 p.

SERRANO, Carlos; WALDMAN, Maurício - Memória d'África: A Temática

Africana em Sala de Aula. São Paulo: Cortez Editora, 2007, 327 p.

SIMÃO, Maria Cristina Rocha. Preservação do Patrimônio Cultural em Cidades. Belo Horizonte: Autêntica Editora, 2001, 128 p.

SOUZA, Laura de Mello. Festas Barrocas e Vida Cotidiana em Minas Gerais. In: JANCSÓ, István; KANTOR, Íris. Festa: Cultura \& Sociabilidade na América Portuguesa. São Paulo: Editora Hucitec/EdUSP/Imprensa Oficial do Estado de São Paulo/FAPESP, 2001, p. 183- 198.

SPIX, Johann Baptist von. Viagem Pelo Brasil: 1817/1820 - Spix e Martius (Volume II). 4 Ed. Tradução de Lúcia F. Lahmeyer. Belo Horizonte: Editora Itatiaia/EdUSP, 1981, 301 p. Original Alemão.

TIRAPELLI, Percival. World Heritage Sites in Brazil. São Paulo: Metalivros, 2000, $287 \mathrm{p}$.

TORELLY, Luiz Philippe Peres. Paisagem Cultural: Uma Contribuição ao Debate. Minha Cidade, v. 9, n. 4. p. 240-244, nov. 2008.

TUAN, Yi - Fu. Topofilia: Um Estudo da Percepção, Atitudes e Valores do Meio Ambiente.Tradução de Lívia de Oliveira. São Paulo: DIFEL, 1980, 288 p. Original Inglês.

VILLELA, Clarisse Martins. Critérios para Seleção de Rochas na Restauração da Cantaria. 2003. 81 f. Dissertação (Mestrado em Engenharia de Materiais) - UFOP/ CETEC/ UEMG (REDEMAT), Ouro Preto (MG), 2003.

ZICO, José Tobias. A Ceia do Caraça. In: MENDES, Nancy Maria. O Barroco Mineiro em Textos. Belo Horizonte: Autêntica Editora, 2003, p. 220-222.

Recebido para publicação em fevereiro de 2011. Aprovado para publicação em novembro de 2011. 